\title{
Analisis dan Pengukuran Tanggapan Frekuensi terhadap Redaman Serat Optik
}

\section{Analysis and Measurement of Frequency Responses Against Optical Fiber Attenuation}

\author{
Uzma Septima, Lince Markis, Ramiati, Andi Ahmad Dahlan \& Sri Nita
}

Jurusan Teknik Elektro Politeknik Negeri Padang Kampus Limau Manis Padang

Telp.0751-72590 Fax.0751-72576 Email: u_septima@yahoo.com

\begin{abstract}
The concept of smart home and cyber home is not the same, even much different. If a smart home or smart home is more aimed at users or home users who lead to conventional homes equipped with digital devices, the concept of cyber home is more to the bandwidth capacity of the internet to complement digital devices in the home. For this reason, Cyber Park Indonesia cooperates with PT Wika Realty. Specifically to develop the housing as a cyber home, Cyber Park Indonesia uses optical fiber. [Kompas, 2017]. This fact states that communication using optical fiber becomes very important so that to optimize the optical fiber system, a study that produces frequency responses to optical fiber attenuation parameters is made. Various sine signal frequency and amplitude values are given as input from an optical fiber dispersing system by looking at the response of the receiver in the form of voltage parameter values. The frequency values given range from $100 \mathrm{~Hz}$ to $10 \mathrm{Khz}$. The linkage of the input amplitude value to the damping value is an output voltage output generated by the amplitude of the amplitude parameter at the sending end. This voltage value comparison is used as the damping parameter of an optical fiber communication system. Giving this frequency will provide the performance of a fiber optic communication system. The resulting voltage value is a constant of changes in the frequency value.
\end{abstract}

Keywords : Optical fiber, Frequency response, Attenuation

\section{PENDAHULUAN}

Konsep smart home dan cyber home tidak sama, bahkan jauh berbeda. Jika rumah cerdas atau smart home lebih ditujukan kepada pengguna atau home user yang mengarah ke rumah konvensional dilengkapi perangkat digital, konsep cyber home lebih kepada kapasitas bandwith internet untuk melengkapi perangkat digital di dalam rumah. Untuk itu Cyber Park Indonesia menggandeng PT Wika Realty. Khusus untuk mengembangkan perumahan tersebut sebagai cyber home, Cyber Park Indonesia menggunakan serat optik. [1].

Tujuan Penelitian ini adalah menghasilkan suatu sistem analisis pengukuran tanggapan frekuensi serat optik terhadap redaman. Penelitian ini menggunakan hasil pengukuran frekuensi pada sisi pengirim yang akan menghasilkan analisis tanggapan frekuensi yang berhubungan dengan nilai redaman serat optik. Hasil pengukuran berupa nilai frekeunsi yang berbeda-beda terhadap nilai tegangan yang dijadikan analisis dalam nilai redaman serat optik Tio Hanif Yanuari (Januari 2018) melakukan penelitian analisis link budget penyambungan serat optik menggunakan optical time domain reflectometer [2].

Slamet Riyadi (April 2016) melakukan penelitian kontribusi kerugian akibat sambungan pada saluran transmisi serat optik single mode [3].

W.Agil (April 2015) telah melakukan analisis rugi-rugi konektor, rugi-rugi penyambungan pada serat optik [4].

Fakta ini menyatakan komunikasi menggunakan serat optik menjadi sangat penting sehingga untuk mengoptimalkan sistem serat optik ini dibuat suatu penelitian yang menghasilkan tanggapan frekuensi 
terhadap parameter redaman serat optik. Parameter suatu redaman sangat penting dalam suatu komunikasi serat optik karena akan menyangkut hasil dari suatu nilai output atau informasi yang diterima pada sisi penerima. Nilai frekuensi dan amplitudo sinyal sinus yang beragam diberikan sebagai input dari suatu sistem pemencar serat optik dengan melihat tanggapan dari penerima berupa nilai parameter tegangan. Nilai frekuensi yang diberikan beragam untuk menguji ketelitian suatu sistem. Keterkaitan dari nilai amplitudo input terhadap nilai redaman adalah suatu nilai tegangan outptut yang dihasilkan akibat oemberian parameter amplitudo pada bagian pengirim. Perbandingan nilai tegangan inilah yang dijadikan parameter redaman dari suatu sistem komunikasi serat optik. Pemberian frekuensi ini akan memberikan performa dari suatu sistem komunikasi serat optik. Karena semua parameter yang ada dalam sistem komunikasi serat optik memberikan kontribusi redaman yang harus diperhitungkan.

\section{METODOLOGI}

Metode dalam pelaksaan pengambilan data dan hasil dilakukan beberapa cara.

\section{Perancangan sistem pengukuran tanggapan frekuensi serat optik terhadap redaman}

Perancangan sistem pengukuran tanggapan frekuensi pada sistem komunikasi serat optik dilakukan dengan membentuk sistem pengukuran pada sisi pengirim dengan mengatur parameter frekuensi dan amplitudo yang bervariasi. Pada sisi penerina dilakukan pengukuran berupa nilai tegangan yang bervariasi sebagai suatu fungsi tegangan terhadap nilai frekuensi. Parameter tegangan pada sisi penerima dijadikan perbandingan terhadap parameter tegangan papa sisi pengirim sehingga terbentuk suatu nilai redaman yang bervariasi sebagai fungsi tanggapan frekuensi sistem serat optik.

\section{Perancangan pengukuran tanggapan frekuensi serat optik terhadap redaman}

Parameter pengukuran tanggapan frekuensi serat optik dilakukan dengan penentuan awal nilai frekuensi dan tegangan yang bervariasi. Parameter yang didapat melalui pengukuran pada sisi penerima berupa nilai tegangan yang bervariasi terhadap nilai frekuensi. Nilai pengukuran tegangan yang bervariasi digunakan dengan bantuan software labsoft sebagai analisa awal dalam penentuan tanggapan frekuensi serat optik terhadap redaman.

Secara keseluruhan bagian dalam konfigurasi sistem ini meliputi :

- Perencanaan sistem tanggapan frekuensi serat optik terhadap redaman.

- Perencanaan hardware terdiri dari sistem pemancar komunikasi serat optik.

- Penggunaan software labsoft untuk mendapatkan parameter pengukuran berupa frekuensi, tegangan dan redaman pada sistem komunikasi serat optik.

\section{Blok Diagaram Rancangan Penelitian Rancangan penelitian secara keseluruhan terdapat pada gambar 1 .}

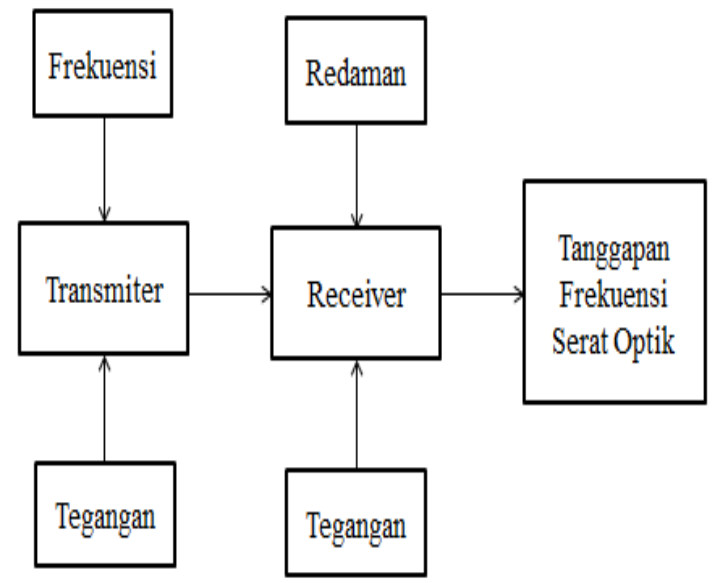

Gambar 1. Diagram Alir Rancangan Penelitian

Laboratorium teknik telekomunikasi serat optik Politeknik Negeri Padang tempat dilakukan penelitian. Dengan teknik pengumpulan data berupa parameter 
frekuensi dan tegangan pada sistem komunikasi serat optik. Parameter frekuensi dan tegangan dijadikan acuan dalam penentuan performa sistem serat optik ini. Perbandingan nilai tegangan output dan input menjadi tolak ukur dalam penentuan nilai redaman sistem komunikasi serat optik.

\section{HASIL DAN PEMBAHASAN}

Pengujian yang telah dilakukan menghasilkan beberapa hal yang dapat dijabarkan sebagai berikut :

\section{Pengukuran Tegangan Pada Transmiter}

Pengukuran tegangan pada transmiter dilakukan dengan pemberian frekuensi yang bervariasi mulai $0.1 \mathrm{~Hz}$ sampai $1000 \mathrm{~Hz}$.

Tabel 1. Pengukuran Tegangan vs Frekuensi

\begin{tabular}{cc}
\hline Frekuensi $(\mathbf{H z})$ & Tegangan $(\mathbf{m v})$ \\
\hline 0.1 & 5.3 \\
1 & 5.3 \\
5 & 5.4 \\
10 & 5.1 \\
50 & 5.4 \\
100 & 5.3 \\
500 & 5.2 \\
800 & 5.3 \\
1000 & 5.4 \\
\hline
\end{tabular}

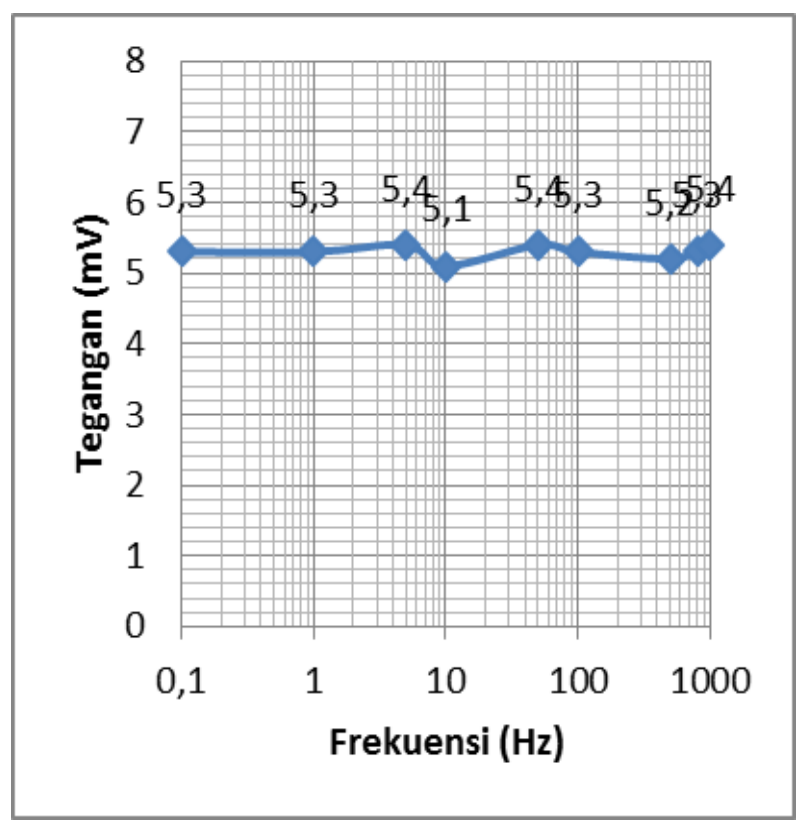

Gambar 2. Grafik Tegangan/Fekuensi TX

\section{Pengukuran Tegangan Pada Sistem Komunikasi Serat Optik}

Pengukuran Tegangan Pada Sistem Komunikasi Serat Optik dilakukan dengan panjang serat optik yang berbeda-beda dan adanya sambungan fusi.

a. Serat Optik dengan Panjang 20 meter Pengukuran tegangan ini dilakukan pada serat optik dengan panjang 20 meter dan kondisi tanpa sambungan fusi.

Tabel 2. Pengukuran Tegangan/Frekuensi $20 \mathrm{~m}$ Tanpa Fusi

\begin{tabular}{cc}
\hline Frekuensi $(\mathrm{Hz})$ & Tegangan $(\mathrm{mv})$ \\
\hline 0.1 & 204 \\
1 & 203 \\
5 & 209 \\
10 & 210 \\
50 & 211 \\
100 & 209 \\
500 & 209 \\
800 & 207 \\
1000 & 207 \\
\hline
\end{tabular}




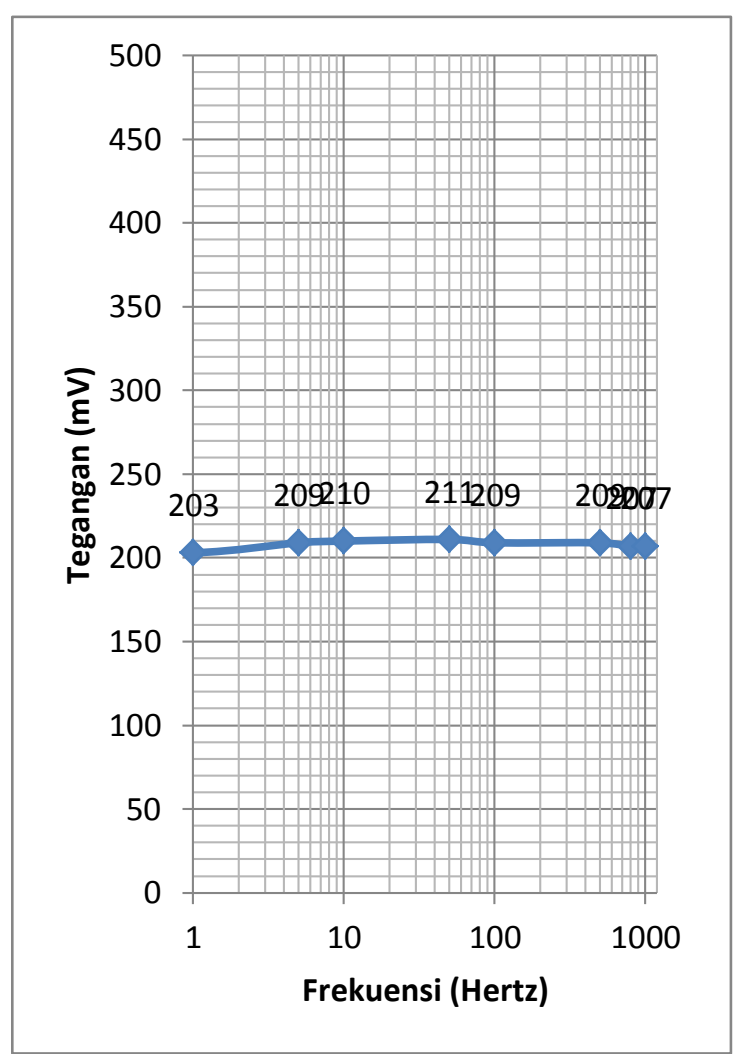

Gambar 3. Grafik Tegangan/Frekuensi 20 m Tanpa Fusi

b. Serat Optik dengan Panjang 40 meter Pengukuran tegangan ini dilakukan pada serat optik dengan kondisi sambungan fusi yang terletak pada jarak 20 meter dan 20 meter redaman $0 \mathrm{~dB}$.

Tabel 3. Pengukuran Tegangan/Frekuensi $40 \mathrm{~m}$ Fusi

\begin{tabular}{cc}
\hline Frekuensi $(\mathrm{Hz})$ & Tegangan $(\mathrm{mv})$ \\
& \\
\hline 0.1 & 8 \\
1 & 8 \\
5 & 8 \\
10 & 8 \\
50 & 8 \\
100 & 8 \\
500 & 9 \\
800 & 10 \\
1000 & 10 \\
\hline
\end{tabular}

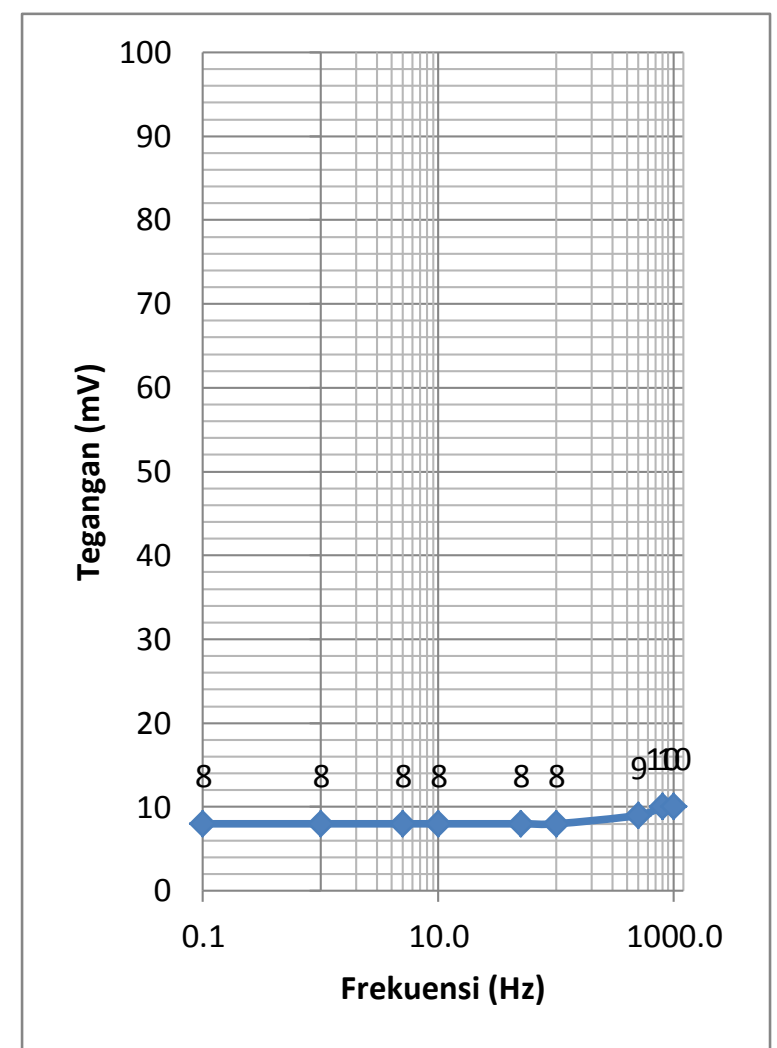

Gambar 4. Grafik Tegangan/Frekuensi $40 \mathrm{~m}$ Fusi

c. Serat Optik dengan Panjang 30 meter Pengukuran tegangan ini dilakukan pada serat optik dengan kondisi sambungan fusi yang terletak pada jarak 20 meter dan 10 meter redaman $0.01 \mathrm{~dB}$.

Tabel 4. Pengukuran Tegangan vs Frekuensi $30 \mathrm{~m}$ Fusi

Frekuensi $(\mathrm{Hz}) \quad$ Tegangan $(\mathrm{mv})$

\begin{tabular}{rr}
\hline 0.1 & 15 \\
1 & 15 \\
5 & 15 \\
10 & 15 \\
50 & 16 \\
100 & 16 \\
500 & 16 \\
800 & 16 \\
1000 & 17 \\
\hline
\end{tabular}




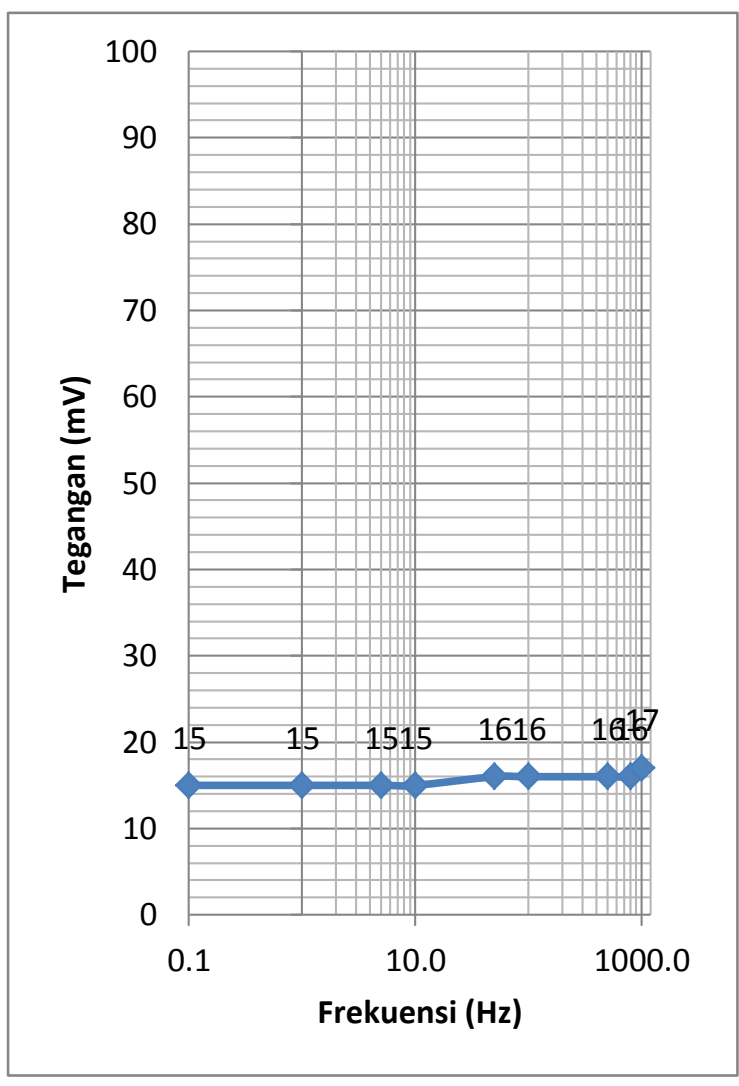

Gambar 5. Grafik Tegangan/Frekuensi $30 \mathrm{~m}$ Fusi

\section{d. Serat Optik dengan Panjang 25 meter} Pengukuran tegangan ini dilakukan pada serat optik dengan kondisi sambungan fusi yang terletak pada jarak 20 meter dan 5 meter redaman $0 \mathrm{~dB}$.

Tabel 5. Pengukuran Tegangan vs Frekuensi 25 m Fusi

\begin{tabular}{cc} 
Frekuensi $(\mathrm{Hz})$ & Tegangan $(\mathrm{mv})$ \\
& \\
\hline 0.1 & 17 \\
1 & 17 \\
5 & 17 \\
10 & 17 \\
50 & 17 \\
100 & 17 \\
500 & 17 \\
800 & 17 \\
1000 & 17 \\
\hline
\end{tabular}

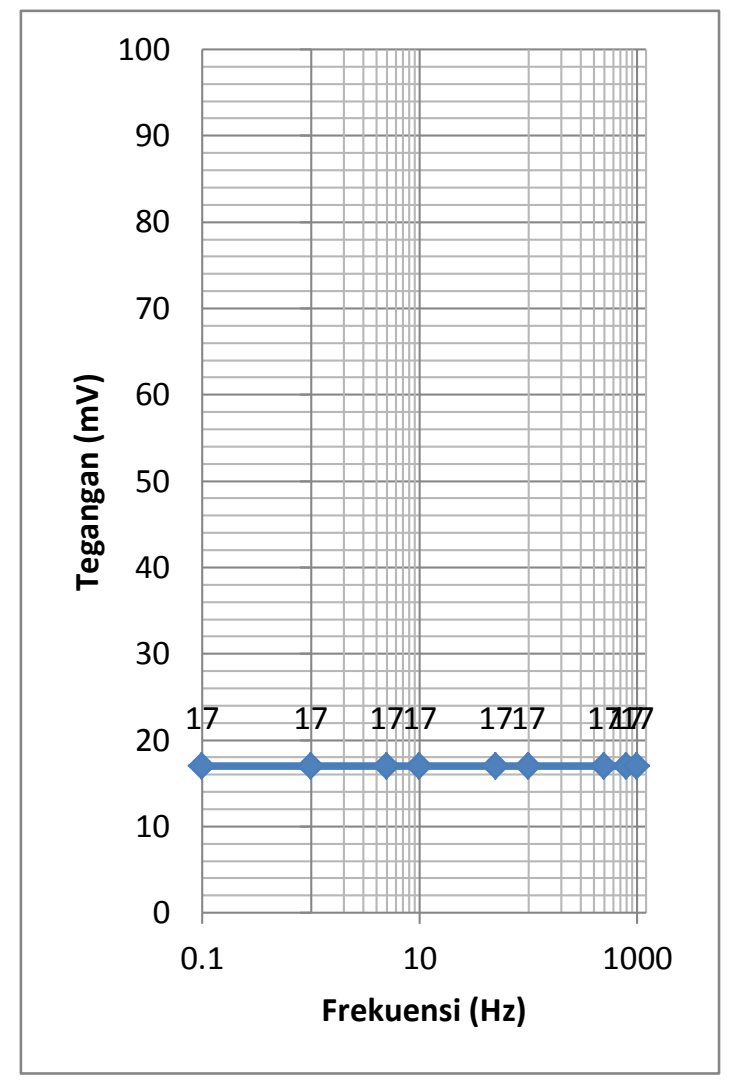

Gambar 6. Grafik Tegangan/Frekuensi $25 \mathrm{~m}$ Fusi

e. Serat Optik dengan Panjang 20 meter Pengukuran tegangan ini dilakukan pada serat optik dengan kondisi sambungan fusi yang terletak pada jarak 10 meter dan 10 meter redaman $0.02 \mathrm{~dB}$.

Tabel 6. Pengukuran Tegangan vs Frekuensi $20 \mathrm{~m}$ Fusi

Frekuensi $(\mathrm{Hz}) \quad$ Tegangan (mv)

\begin{tabular}{rl}
\hline 0.1 & 14 \\
1 & 14 \\
5 & 14 \\
10 & 14 \\
50 & 15 \\
100 & 15 \\
500 & 15 \\
800 & 15 \\
1000 & 15 \\
\hline
\end{tabular}




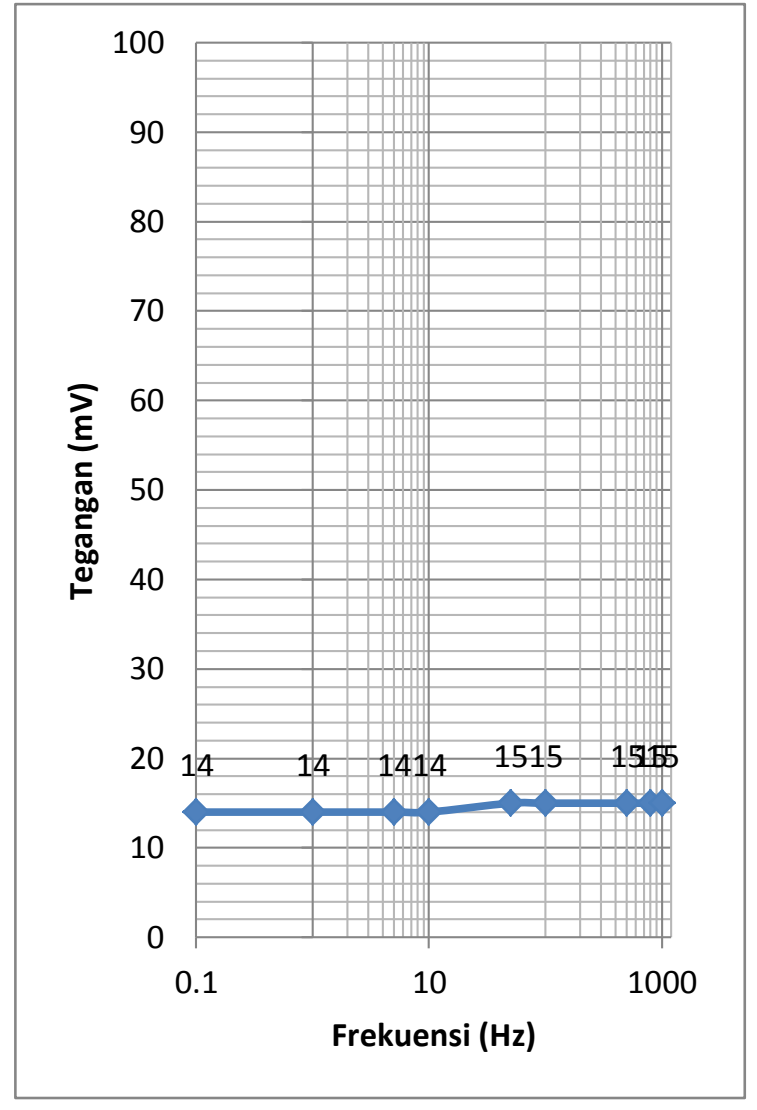

Gambar 7. Grafik Tegangan/Frekuensi 20 m Fusi

\section{f. Serat Optik dengan Panjang 15 meter}

Pengukuran tegangan ini dilakukan pada serat optik dengan kondisi sambungan fusi yang terletak pada jarak 10 meter dan 5 meter redaman $0 \mathrm{~dB}$.

Tabel 7. Pengukuran Tegangan vs Frekuensi $15 \mathrm{~m}$ Fusi

\begin{tabular}{cc}
\hline Frekuensi $(\mathrm{Hz})$ & Tegangan $(\mathrm{mv})$ \\
\hline 0.1 & 16 \\
1 & 16 \\
5 & 16 \\
10 & 16 \\
50 & 17 \\
100 & 17 \\
500 & 17 \\
800 & 17 \\
1000 & 17 \\
\hline
\end{tabular}

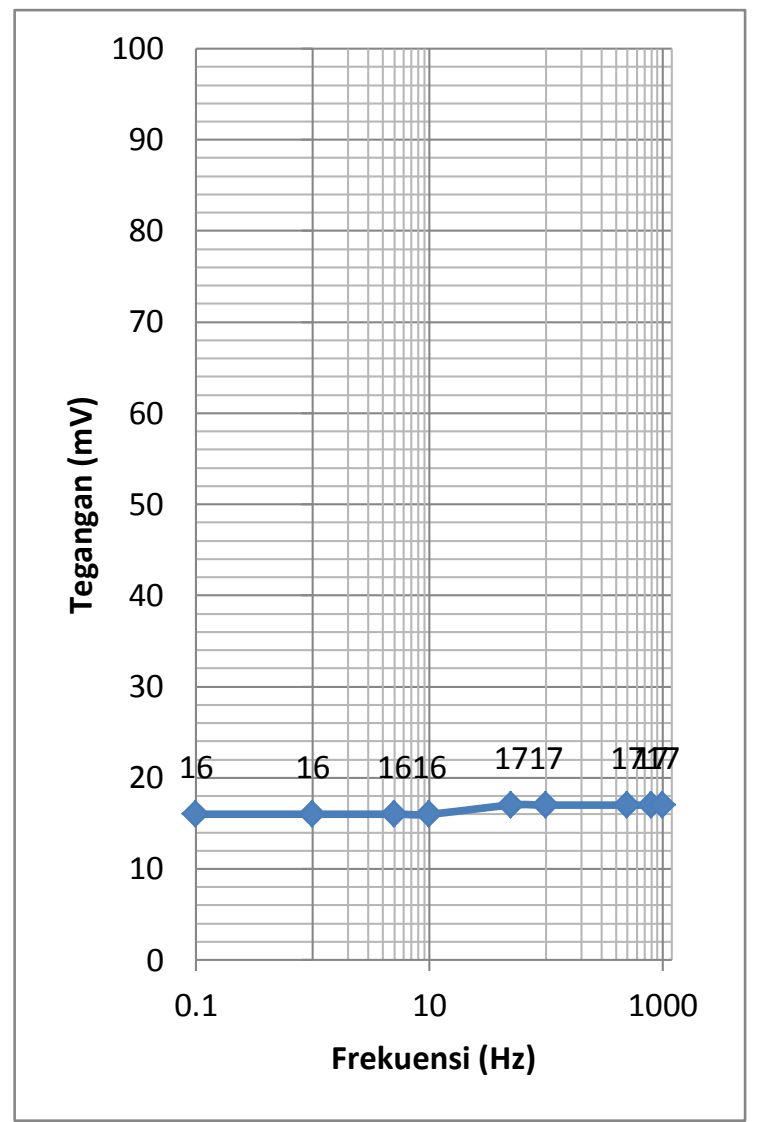

Gambar 8. Grafik Tegangan/Frekuensi $15 \mathrm{~m}$ Fusi

\section{g. Serat Optik dengan Panjang 10 meter} Pengukuran tegangan ini dilakukan pada serat optik dengan kondisi sambungan fusi yang terletak pada jarak 5 meter dan 5 meter redaman $0.01 \mathrm{~dB}$.

Tabel 8. Pengukuran Tegangan vs Frekuensi 10 m Fusi

\begin{tabular}{cc} 
Frekuensi $(\mathbf{H z})$ & Tegangan $(\mathbf{m v})$ \\
& \\
\hline 0.1 & 15 \\
1 & 15 \\
5 & 16 \\
10 & 16 \\
50 & 16 \\
100 & 16 \\
500 & 16 \\
800 & 16 \\
1000 & 16 \\
\hline
\end{tabular}




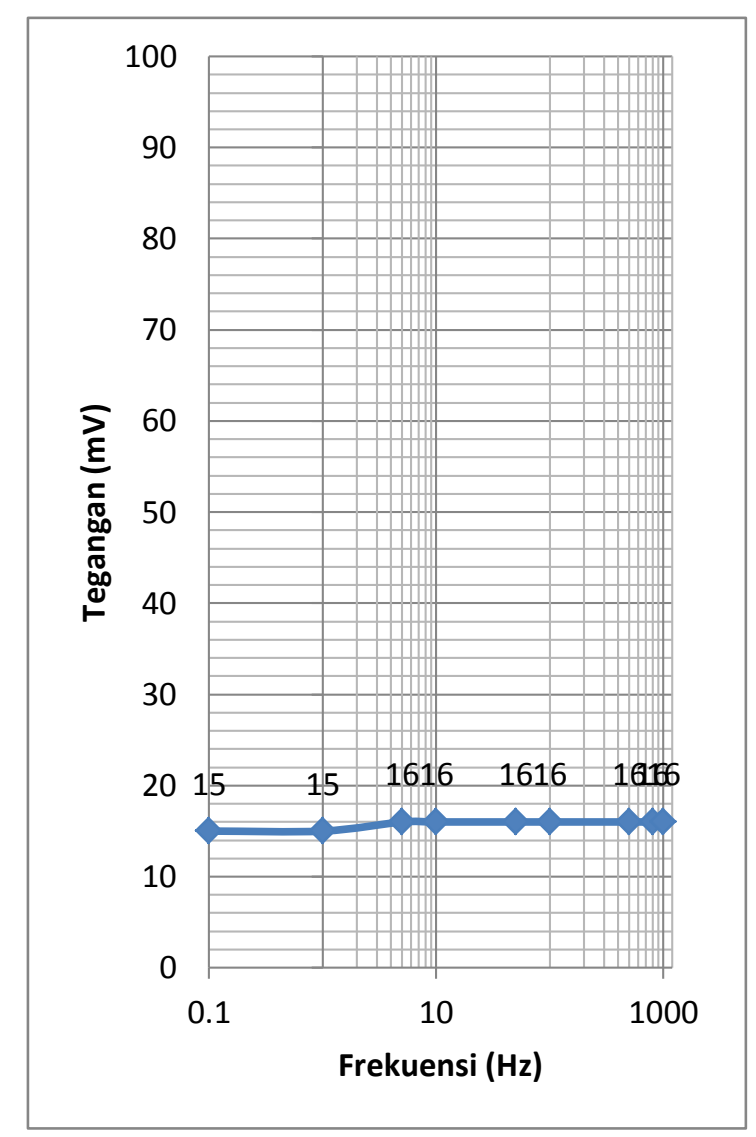

Gambar 9. Grafik Tegangan/Frekuensi $10 \mathrm{~m}$ Fusi

\section{SIMPULAN}

Kesimpulan yang dapat dirumuskan dalam pelaksanaan dari hasil penelitian ini adalah :

1. Nilai tegangan yang dihasilkan rata-rata konstan terhadap perubahan nilai frekuensi.

2. Nilai tegangan yang dihasilkan pada saat ada sambungan fusi rata-rata konstan terhadap perubahan nilai frekuensi.

3. Nilai Tegangan yang dihasilkan tanpa sambungan fusi lebih besar dari nilai tegangan dengan sambungan fusi pada serat optik.

\section{UCAPAN TERIMA KASIH}

Terima kasih kepada Politeknik Negeri Padang yang telah memberikan dana DIPA dalam penelitian ini dan semua pihak yang telah membantu terlaksananya penelitian ini. Nomor Kontrak : 361/PL9 .1.4/ PT.0.1.02/2019

\section{DAFTAR PUSTAKA}

[1] Harian Kompas, https://www.kompas. com/tag/kaleidoskop-2017

[2] Tio Hanif Yanuary "Analisis link budget penyambungan serat optik menggunakan optical time domain reflectometer" Jurnal teknik elektro , “ Vol 10 No 1, Januari 2018

[3] S Riyadi "Kontribusi kerugian akibat sambungan pada saluran transmisi serat optik single mode" Simetris, Vol. 7 No.1, April 2016

[4] W Agil "Analisis rugi-rugi konektor, rugi-rugi penyambungan pada serat optik” USU, vol 11 No 29, April 2015.

[5] Yosi Wismaya, Lucia Jambola “ Analisis kinerja sistem penyambungan serat optik menggunakan metoda fusion splicing pada ruas Soreang-Nanjung" Transistor El semarang, vol 3 No.1, 2018 .

[6] The Fiber Optic Association. (2009). Topic : Fusion Splicing. Retrieved from www.thefoa.org.

[7] Massa, Nick. (2000).'Fiber Optic Telecommunication". Springfield Technological Community College : Springfield, Massachusetts.G. Eason, B. Noble, and I. N. Sneddon, On certain integrals of Lipschitz-Hankel type involving products of Bessel functionsPhil. Trans. Roy. Soc. London. vol. A247, pp. 529-551, April 1955. 